\title{
Intractable diarrhea in a newborn infant: Microvillous inclusion disease
}

\author{
Wendy Wilson ${ }^{1}$, R Brent Scott MDCM ${ }^{1}$, Alfredo Pinto MD $^{2}$, Marli A Robertson MBChB ${ }^{1}$
}

\begin{abstract}
W Wilson, RB Scott, A Pinto, MA Robertson. Intractable diarrhea in a newborn infant: Microvillous inclusion disease. Can J Gastroenterol 2001;15(1):61-64. A newborn male presented with watery diarrhea, dehydration and metabolic acidosis. Severe secretory diarrhea of variable magnitude persisted when the patient was on parenteral nutrition with no oral intake. Initial light microscopic evaluation of a small intestinal mucosal biopsy showed partial villous atrophy and crypt hypoplasia. Ultrastructural studies of the villous enterocyte revealed internalized inclusions of microvilli, typical of microvillous inclusion disease. Presented are a case report and a discussion of the differential diagnosis of watery diarrhea in the neonate, as well as a short review of microvillous inclusion disease.
\end{abstract}

Key Words: Diarrhea; Infant; Microvillous inclusion disease; Newborn; Small intestine

\section{Diarrhée rebelle chez un nouveau-né : Maladie d'inclusion des microvillosités}

RÉSUMÉ : Un nouveau-né de sexe masculin a été amené pour diarrhée liquide, déshydratation et acidose métabolique. La diarrhée sécrétoire marquée a persisté selon une intensité variable lorsque le jeune patient se trouvait sous nutrition parentérale, sans apport par voie orale. Un examen par microscopie électronique d'une biopsie de la muqueuse du grêle a révélé une atrophie villeuse partielle et une hypoplasie cryptique. Des études ultrastructurelles des entérocytes villeux a révélé des inclusions internes de microvillosités typiques de la maladie d'inclusion des villosités. Le présent article propose un rapport de cas et une discussion du diagnostic différentiel de la diarrhée liquide chez le nouveau-né et un bref survol de cette maladie.
$\mathrm{I}$ nfants who present with protracted watery diarrhea and failure to thrive pose a difficult diagnostic and therapeutic problem. We report the case of a neonate presenting with microvillous inclusion disease (MID). We discuss the differential diagnosis of watery diarrhea in the infant and the pathophysiology of MID.

\section{CASE PRESENTATION}

A nine-day-old white male presented with a history of watery diarrhea that had developed gradually in the first few days after birth. He was born to nonconsanguineous parents at 36 weeks' gestation. The pregnancy was uncomplicated, with no evidence of polyhydramnios. There was meconium-stained liquor at delivery, but the immediate postnatal period was uneventful. Birth weight was $2.74 \mathrm{~kg}$. The patient was discharged on day 3 weighing $2.43 \mathrm{~kg}$. At home, he was breastfed every 2 to $3 \mathrm{~h}$ and continued to have three stools per day, of which at least one was described as watery. On day 9, he was brought to the hospital because he was lethargic and feeding poorly. In the emergency room, he was noted to be poorly responsive and was estimated to be $10 \%$ dehydrated, weighing only $1.8 \mathrm{~kg}$. The physical examination was otherwise unremarkable. He was hypernatremic and acidotic, with a capillary blood $\mathrm{pH}$ of 6.97 but only a modest anion gap of $22 \mathrm{mmol} / \mathrm{L}$ (normal 5 to $15 \mathrm{mmol} / \mathrm{L}$ ). Oral feeding was stopped, and fluids were replaced intravenously. Bicarbonate was infused to partially correct the acidosis. Broad spectrum antibiotic therapy was initiated after cultures were taken. Of the many possible causes of watery diarrhea (Table 1 ), a viral or allergic enteropathy was initially considered to be most likely. However, stool cultures and rapid screens for rotavirus and adenovirus were subsequently negative. Blood, urine and cerebrospinal fluid were sterile.

On resumption of breastfeeding on day 3 of admission,

Departments of ${ }^{1}$ Pediatrics and ${ }^{2}$ Pathology, University of Calgary, Calgary, Alberta

Correspondence and reprints: Dr Marli Robertson, Department of Pediatrics, Health Science Centre, 3330 Hospital Drive NW, Calgary,

Alberta T2N 4N1. Telephone 403-220-4540, fax 403-283-3028, e-mail robertsm@ucalgary.ca

Received for publication June 30, 1999. Accepted September 20, 1999 
TABLE 1

Differential diagnosis of watery diarrhea in the infant

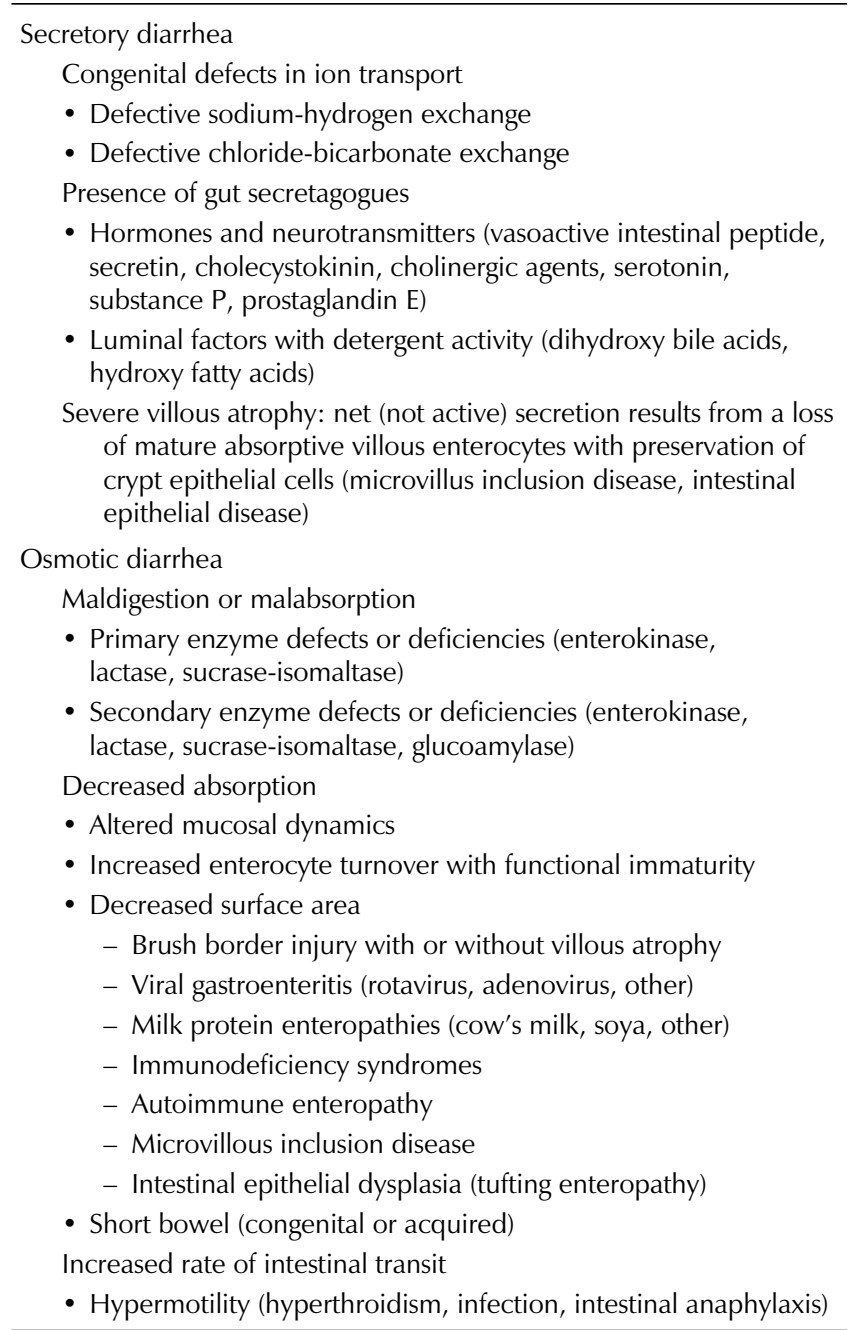

Data from references 26 to 28

the patient had eight to 10 large watery stools per day (negative for fat and slightly positive for reducing substances), and again rapidly became dehydrated and acidotic. After a period of bowel rest, he failed successive trials of enteral feeding, including glucose-electrolyte solution, Pregestimil (Mead Johnson, USA) - which is hydrolyzed cows' milk protein and glucose polymer - and then lambs' meat-based formula. With each trial, he developed a markedly distended abdomen, irritability, frequent watery bowel motions and metabolic acidosis. On total parenteral nutrition, fluid and electrolyte requirements remained very high (higher than $250 \mathrm{~mL} / \mathrm{kg} /$ day), and he demonstrated a persistent tendency to develop a nonanion gap metabolic acidosis. This was managed by constant infusion of supplemental bicarbonate or acetate. Stool electrolyte concentrations in the fed and fasting states were similar, and confirmed the clinical evidence that this was predominantly a secretory diarrhea. Stool electrolyte levels were as follows: stool sodium 65 to $86 \mathrm{mmol} / \mathrm{L}$, potassium 25 to $52 \mathrm{mmol} / \mathrm{L}$, chloride 73 to $85 \mathrm{mmol} / \mathrm{L}$ and bicarbonate $20 \mathrm{mmol} / \mathrm{L}$.

A barium study showed no evidence of a congenital short

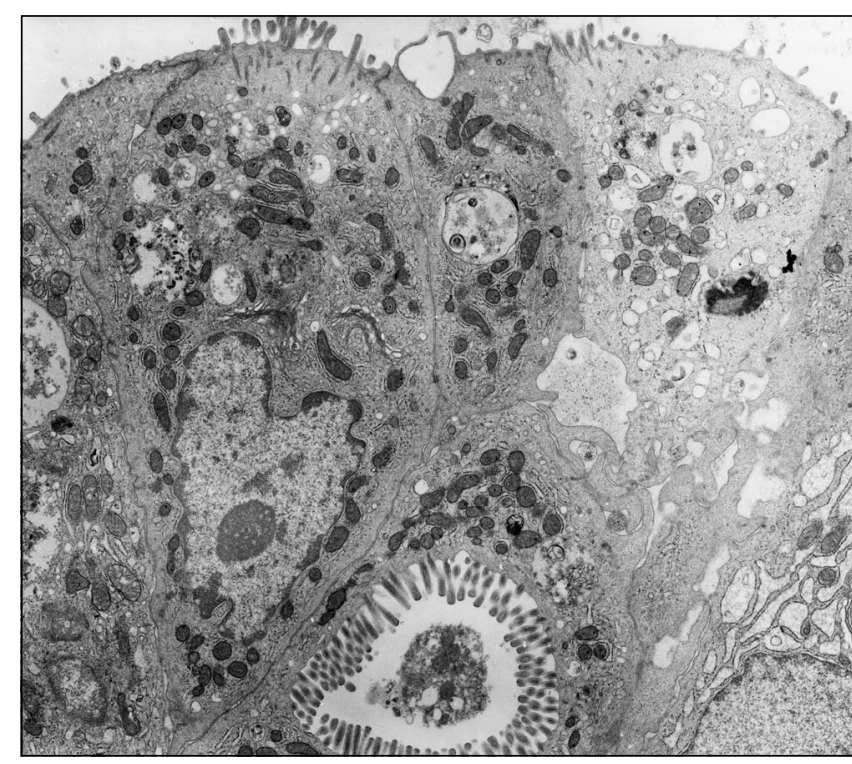

Figure 1) Electron micrograph of a jejunal biopsy showing intracytoplasmic inclusions lined by intact microvilli in the superficial enterocytes. Note the poorly developed brush border with irregular and shortened microvilli, and the presence of vesicular bodies in the apical cytoplasm (uranil acetate-lead citrate, original magnification $\times 5000$ )

bowel or an obstruction. Hirschsprung's disease was excluded when a full thickness rectal biopsy showed normal ganglion cells. Urinary catecholamines were assessed to rule out a neuroendocrine tumour and were reported to be in the normal range. Assessments revealed no immunological abnormality. At four months of age, when the patient weighed $3.0 \mathrm{~kg}$, endoscopic duodenal biopsies were obtained. With examination by light microscopy, sections of small intestinal mucosa exhibited partial to total villous atrophy, a hypocellular lamina propria and crypt hypoplasia. The poorly defined brush border in the surface epithelium and the periodic acid-Schiff positivity of the apical cytoplasm of the enterocytes suggested MID (1). Suction biopsies of the rectal mucosa were unremarkable. Because of the increased risk of perforation associated with suction jejunal biopsies in malnourished infants, repeat jejunal biopsy with a Carey capsule and primary fixation of tissue for electron microscopy were delayed until the child was six months of age and weighed $5.5 \mathrm{~kg}$. Electron microscopic evaluation of this second proximal small intestinal biopsy revealed intracytoplasmic microvillous inclusion bodies, confirming the diagnosis of MID (Figure 1).

The patient, maintained on total parenteral nutrition, developed cholestatic liver disease, and was listed for hepatic and small intestinal transplantation. He died from complications of sepsis at the age of 17 months. An autopsy was not performed.

\section{DISCUSSION}

The initial report of an apparently familial enteropathy, characterized by protracted diarrhea from birth and hypoplastic villous atrophy, was in 1978 by Davidson et al (2). Electron microscopy of surface enterocytes from a jejunal biopsy speci- 
men of one of their patients revealed intracytoplasmic inclusions composed of neatly arranged brush border microvilli. Similar inclusions have since been reported in other children presenting with protracted watery diarrhea starting soon after birth (1-11). The term 'MID' was proposed to designate the condition because it highlights the characteristic ultrastructural lesion and clearly differentiates the condition from other entities (1). The condition appears to be inherited as an autosomal recessive disorder (1-5). While consanguinity was not present in our case, Candy et al (5) found that $20 \%$ of infants with this disease were the products of consanguineous relationships, and three of the nine infants reported by Cutz et al (1) had a sibling affected. A high frequency of MID in the Navajo Indian population of Arizona has been observed (11). While uncommon, MID is the most common cause of severe refractory diarrhea in the neonatal period in North America.

Distinctive intracytoplasmic inclusions are found in the absorptive cells of the small intestine and have been described in colonocytes in MID (1). However, as in this case, colonocytes may be normal (12). This suggests that there may be variability in the severity of this disorder or perhaps even different molecular defects resulting in a similar phenotype. MID is also characterized pathologically by a severe, generalized, hypoplastic enteropathy of the small intestine. A variable degree of villous atrophy is also seen in intestinal epithelial dysplasia or 'tufting' disease, another cause of intractable diarrhea in infancy. The characteristic finding in intestinal epithelial dysplasia is disorganization of the surface enterocytes with focal tufting (13). Unlike these two causes of neonatal diarrhea, the ultrastructure of the enterocyte is normal in congenital chloride diarrhea (14), diarrhea secondary to defective sodium-hydrogen exchange (15), primary malabsorption of bile acids (16) and congenital short bowel (17).

Watery diarrhea in the neonate may also be due to carbohydrate malabsorption, which results in primarily osmotic diarrhea. In our patient, the diagnosis of secretory diarrhea was supported by the persistence of profuse watery diarrhea when not being fed, the absence of a stool osmolar gap when fed monosaccharide-containing formulas, and elevated sodium and chloride concentrations in the stool.

The history was not typical of congenital chloride diarrhea or diarrhea secondary to a deficiency of sodiumhydrogen exchange. These disorders are both characterized by a maternal history of polyhydramnios (consistent with intrauterine diarrhea) and abdominal distension of the neonate at birth. Our patient and other patients reported to have MID do not have these features, although the reason for the postnatal onset of diarrhea is not known (1). In addition, patients with congenital chloride diarrhea develop metabolic alkalosis, while our patient was typical of patients previously reported to have MID, in that he manifested acidosis due to bicarbonate loss in the stools.

The functional consequence of hypoplastic enteropathy is an inability to absorb ingested nutrients and profuse watery diarrhea resulting from a net secretory state in the intestine (1-4). In vivo and in vitro studies of small intestinal electrolyte transport in these infants suggest that while mucosal surface area is much impaired, mucosal enterocytes retain the capacity for limited but active sodium-dependent mucosal to serosal glucose transport. Also, the watery diarrhea results from a combination of reduced mucosal to serosal ion fluxes, and elevated basal secretion of both chloride and sodium ions $(2,18,19)$. While it has never been investigated, the possibility of a dysregulated, sodium-coupled, bicarbonate secretory process may explain the elevated basal sodium secretion and the massive luminal losses of bicarbonate that were observed in this infant and that are typical of MID. Another possible explanation, at a molecular level, for the massive secretory diarrhea seen in these patients (despite apparent crypt hypoplasia) was posed by Michail et al (20). That study showed that the mRNA expression of three apical transporters involved in sodium absorption - sodium hydrogen exchangers (NHE-2 and NHE-3), and the sodium glucose transporter (SGLT1) - were markedly reduced. These data suggest that the morphological changes of MID are associated with secondary decreases in mRNA coding for apically located ion transport proteins.

While the basic defect is unknown, it has been proposed that the ultrastructural lesion that characterizes MID is best explained as an example of a normal cell component assembled in an abnormal location (1). The microvilli appear to be assembled on the inner surface of the intracytoplasmic vesicles rather than at the apical cell surface. Furthermore, the prominent periodic acid-Schiff staining of the apical cytoplasm (rather than the brush border), the immunofluorescent staining of specific brush border enzymes in the apical cytoplasm and the accumulation of secretory granules in the apical region of some cells all suggest that an abnormality of exocytosis exists $(1,19,21)$. Brush border proteins normally reach the plasma membrane at the base of the apical microvilli. They are synthesized in the rough endoplasmic reticulum, processed and assembled as membrane proteins in the Golgi apparatus, and transported to the cell surface along a chain of connecting intracytoplasmic vesicles. However, against this theory, normal exocytosis and localization of two brush border-targeted enzymes (sucrase-isomaltase and dipeptidylpeptidase intravenous) have been demonstrated in biopsies and organ cultures from MID patients (22). These studies suggested that both direct and indirect constitutive pathways of exocytosis were intact in MID. It was hypothesized that there may be an as yet uncharacterized regulated pathway of exocytosis in enterocytes that is abnormal in MID.

Aberrant assembly of microvilli with microvillous inclusions can be produced by agents such as colchicine and cytochalasin, which interfere with intracellular trafficking by disrupting microtubules and microfilaments (1). Analysis of brush border membrane proteins from a patient with MID showed a paucity of a myosin-like protein compared with controls, supporting the hypothesis that this may be a disease of the brush border cytoskeleton, which leads to the distinctive morphology (23).

Empirical trials of various medical therapies, including high dose corticosteroid, pentagastrin, human colostrum, 
epidermal growth factor, clonidine, and somatostatin or its long acting analogue octreotide, have been reported (1-4). Of these, only somatostatin or its analogue octreotide was effective in decreasing the volume of diarrhea and preventing recurrent episodes of dehydration (24). However, in no instance has medical therapy prevented reliance on parenteral nutrition and intravenous fluid replacement therapy for massive, ongoing intestinal losses. Mortality is high (diarrhea persists until death in $80 \%$ of cases [5]), with death generally occurring before 18 months of age (1). Intestinal transplantation is the only effective treatment for MID. Oliva et al (12) reported the first successful small intestinal transplant in a girl who was two-and-a-half years old (12); subsequently, Herzog et al (25) reported a successful combined bowel-liver transplantation in a boy who was seven months old.

While MID is a rare cause of diarrhea, accurate diagnosis is important because it appears to be an autosomal recessive disease with a high mortality, and genetic counselling of the child's parents is essential. Further investigation of the pathophysiology of this condition may reveal important insights into enterocyte biology.

ACKNOWLEDGEMENTS: Wendy Wilson, a medical student at the University of Saskatchewan, prepared this manuscript during an elective in pediatric gastroenterology and nutrition at the Alberta Children's Hospital. The authors thank Dr E Cutz of the Department of Pathology of the Hospital for Sick Children in Toronto, Ontario for expert review of pathological specimens.

\section{REFERENCES}

1. Cutz E, Rhoads JM, Drumm B, Sherman P, Durie P, Forstner G. Microvillous inclusion disease: an inherited defect of the brush border assembly and differentiation. N Engl J Med 1989;320:646-51.

2. Davidson GP, Cutz E, Hamilton JR, Gall DG. Familial enteropathy: a syndrome of protracted diarrhea from birth, failure to thrive, and hypoplastic villous atrophy. Gastroenterology 1978;75:783-90.

3. Phillips AD, Schmitz J. Familial microvillous atrophy: a clinicopathological survey of 23 cases. J Pediatr Gastroenterol Nutr 1992;14:380-96.

4. Davidson G. Enteropathies of unknown origin. In: Walker WA, Durie PR, Hamilton JR, Walker-Smith JA, Watkin JB, eds. Pediatric Gastrointestinal Disease. Pathophysiology, Diagnosis, and Management, 2nd edn. St Louis: Mosby Year Book Inc, 1996:862-7.

5. Candy DCA, Larcher CF, Cameron DJS, et al. Lethal familial protracted diarrhea. Arch Dis Child 1981;56:15-23.

6. Fisher SE, Boyle JT, Holtzapple P. Chronic protracted diarrhea and jejunal atrophy in an infant. Dig Dis Sci 1981;26:181-6.

7. Goulet JM, Boccon-Gibod L, Chatelet F, Ploussard JP, Navarro J, Polonovski C. Familial protracted diarrhea with hypoplastic villous atrophy: report of two cases. Pediatr Res 1982;16:1046. (Abst)

8. Schmitz J, Ginies JL, Arnaud-Battandier F, et al. Congenital microvillous atrophy: a rare cause of neonatal intractable diarrhea. Pediatr Res 1982;16:1014.
9. Phillips AD, Jenkins P, Raafat F, Walker-Smith JA. Congenital microvillous atrophy: specific diagnostic features. Arch Dis Child 1985;60:135-40.

10. Nathavitharana KA, Green NJ, Raafat F, Booth IW. Siblings with microvillous inclusion disease. Arch Dis Child 1984;71:71-5.

11. Pohl JF, Shub MD, Trevelline EE, et al. A cluster of microvillous inclusion disease in the Navajo population. J Pediatr 1999;134:103-6.

12. Oliva M, Permand J, Saa Vedra J, Young-Ransarant J, Schwarz K. Successful intestinal transplantation for microvillous inclusion disease. Gastroenterology 1994;106:771-4.

13. Reifen RM, Cutz E, Griffiths AM, Ngan BO, Sherman P. Tufting enteropathy: a newly recognized clinicopathological entity associated with refractory diarrhea in infants. J Pediatr Gastroenterol Nutr 1994;18:379-85.

14. Holmberg C, Perheentupa J, Launiala K, Hallman N. Congenital chloride diarrhoea: clinical analysis of 21 Finnish patients. Arch Dis Child 1977;52:255-67.

15. Booth IW, Strang G, Mura H, Festoon TR, Mill PJ. Defective jejunal brush-border $\mathrm{Na}^{+} / \mathrm{H}^{+}$exchange: a cause of congenital secretory diarrhoea. Lancet $1985 ; \mathrm{i}: 1066-9$.

16. Balistreri WF, Partin JC, Schubert WK. Bile acid malabsorption a consequence of terminal ileal dysfunction in protracted diarrhea of infancy. J Pediatr 1977;90:21-8.

17. Hamilton JR, Reilly BJ, Morecki R. Short small intestine associated with malrotation: a newly described congenital cause of intestinal malabsorption. Gastroenterology 1969;56:124-36.

18. Rhoads JM, Vogler RC, Lacey SR, et al. Microvillous inclusion disease. In vitro jejunal electrolyte transport. Gastroenterology 1991;100:811-7.

19. Cutz E, Sherman PM, Davidson GP. Enteropathies associated with protracted diarrhea of infancy: clinicopathological features, cellular and molecular mechanisms. Pediatr Pathol Lab Med 1997; 17:335-67.

20. Michail S, Collins JF, Xu H, Kaufman S, Vanderhoof J, Ghishan FK. Abnormal expression of brush-border membrane transporters in the duodenal mucosa of two patients with microvillus inclusion disease. J Pediatr Gastroenterol Nutr 1998;27:536-42.

21. Lake BD. Microvillus inclusion disease: specific diagnostic features shown by alkaline phosphatase histochemistry. J Clin Pathol 1998;41:880-2.

22. Phillips A, Fransen J, Hauri H-P, Sterchi E. The constitutive exocytotic pathway in microvillous atrophy. J Pediatr Gastroenterol Nutr 1993;17:239-46.

23. Carruthers L, Phillips AD, Dourmashkin R, Walker-Smith JA. Biochemical abnormality in brush border membrane protein of a patient with congenital microvillus atrophy. J Pediatr Gastroenterol Nutr 1985;4:902-7.

24. Couper RT, Berzen A, Berall G, Sherman PM. Clinical response to the long acting somatostatin analogue SMS 201-995 in a child with congenital microvillous atrophy. Gut 1989;30:1020-4.

25. Herzog D, Atkinson P, Grant D, Paradis K, Williams S, Seidman E. Combined bowel-liver transplantation in an infant with microvillous inclusion disease. J Pediatr Gastroenterol Nutr 1996;23:405-8.

26. Ghishan F. Secondary enzyme deficiencies. In: Walker WA, Durie PR, Hamilton JR, Walker-Smith JA, Watkin JB, eds. Pediatric Gastrointestinal Disease. Pathophysiology, Diagnosis and Management, 2nd edn. St Louis: Mosby Year Book Inc, 1996;786-91.

27. Riedel B, Ghishan F. Acute diarrhea. In: Walker WA, Durie PR, Hamilton JR, Walker-Smith JA, Watkin JB, eds. Pediatric Gastrointestinal Disease. Pathophysiology, Diagnosis and Management, 2nd edn. St Louis: Mobsy Year Book Inc, 1996;251-62.

28. Dobbins JW, Binder HJ. Pathophysiology of diarrhea: alterations in fluid and electrolyte transport. Clin Gastroenterol 1981;10:605-25. 


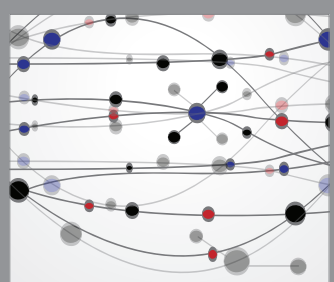

The Scientific World Journal
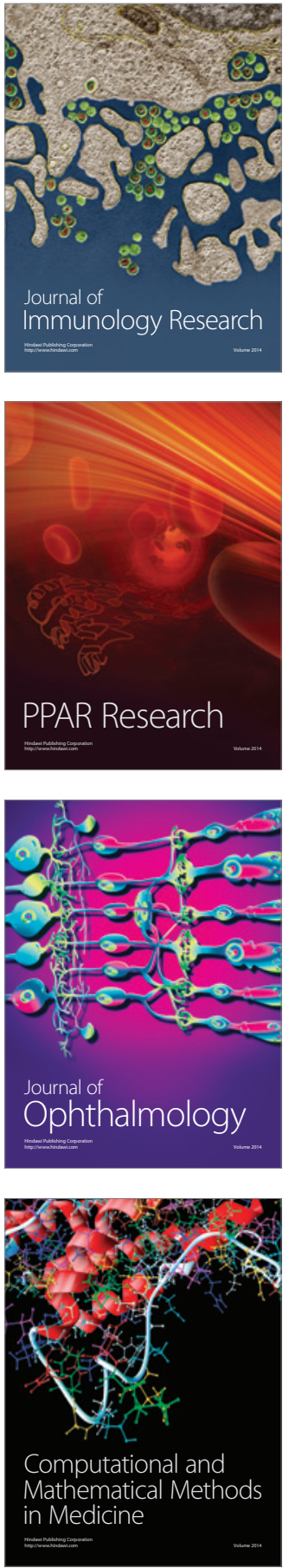

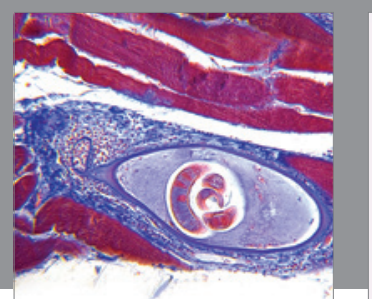

Gastroenterology Research and Practice

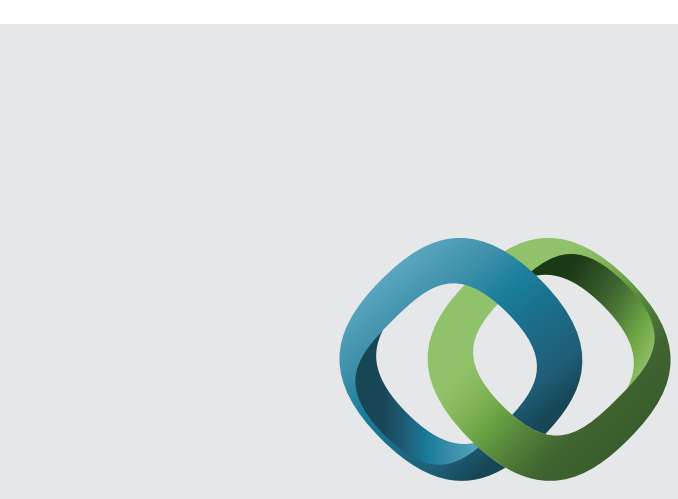

\section{Hindawi}

Submit your manuscripts at

http://www.hindawi.com
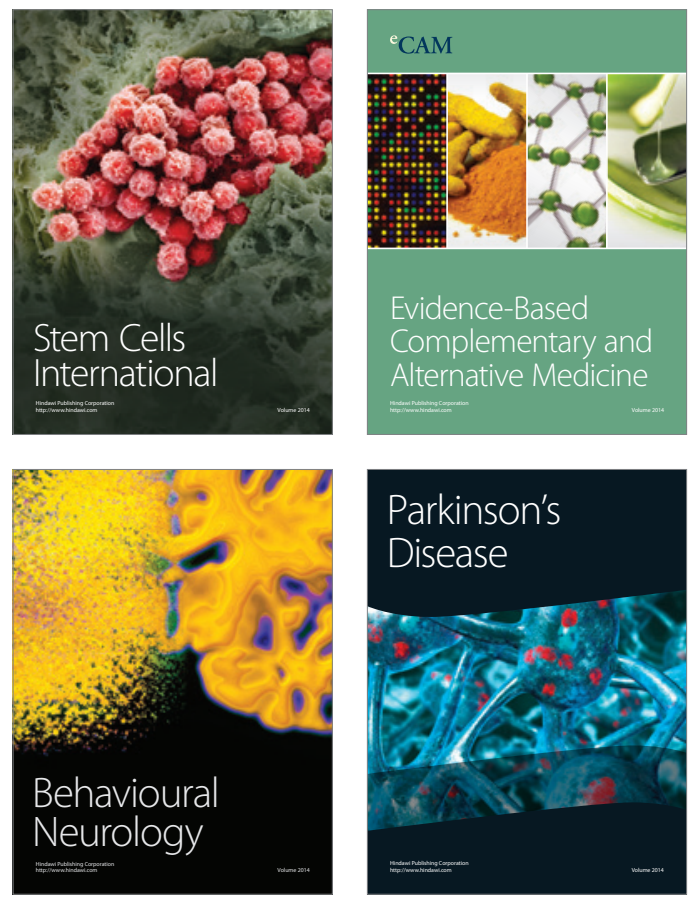
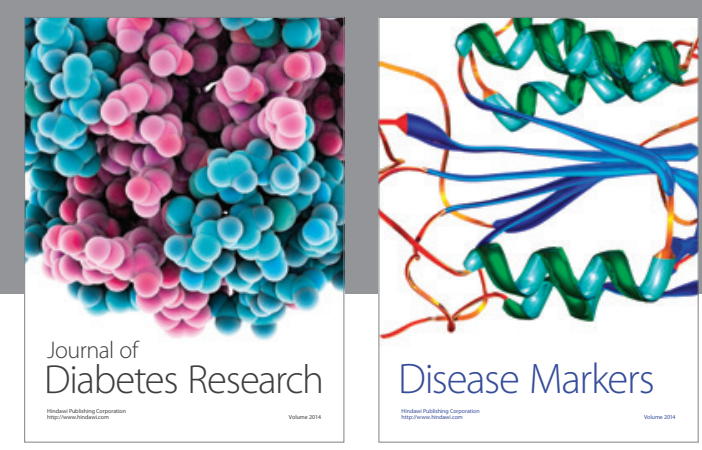

Disease Markers
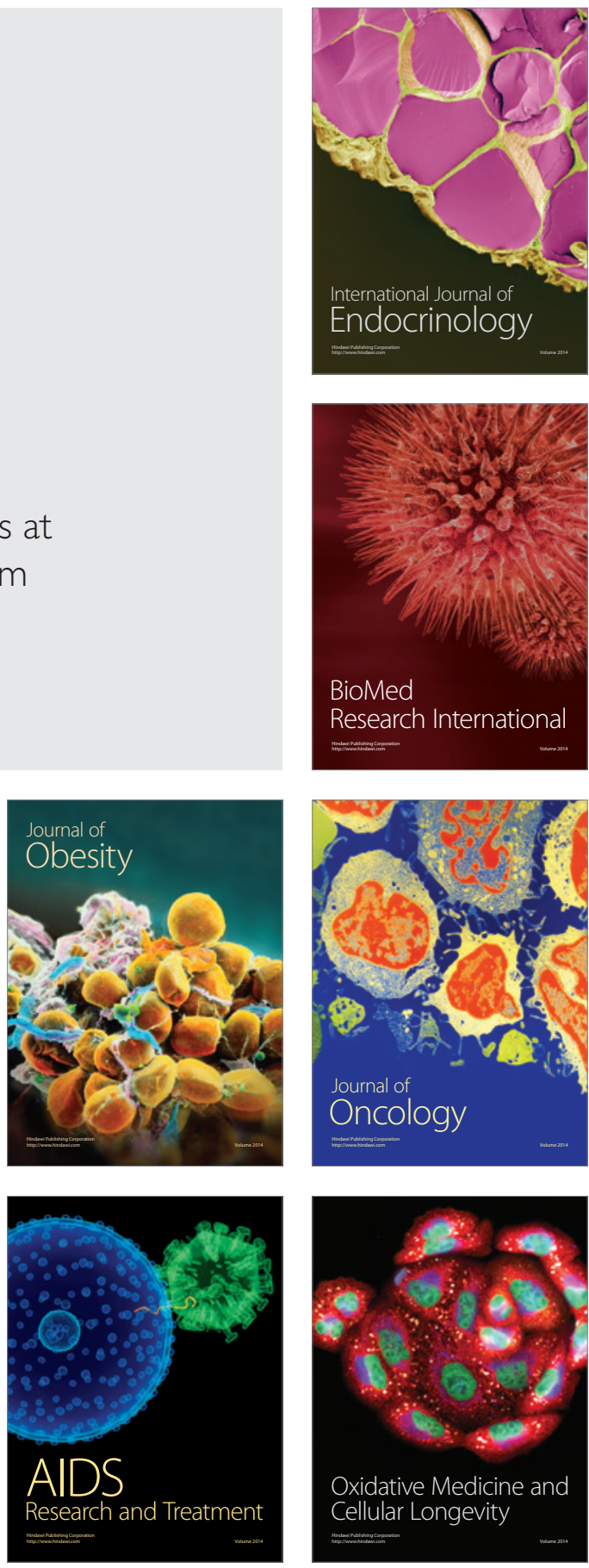